\title{
Ageing evolution of foamed warm mix asphalt combined with reclaimed asphalt pavement
}

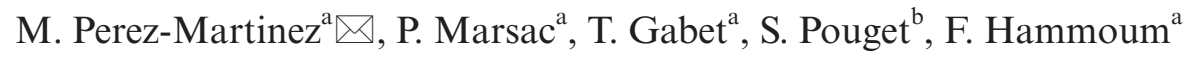 \\ a. LUNAM Université, IFSTTAR, MAST, (Bouguenais, France) \\ b. EIFFAGE Travaux Publics, Direction Recherche \& Innovation, (Corbas, France) \\ $\triangle$ miguel.perez-martinez@ifsttar.fr
}

\begin{abstract}
The combination of high rates of reclaimed asphalt pavement (RAP) and warm mix asphalt (WMA) technologies is still ambiguous in terms of durability. With the aim of clarifying this issue, a study comparing a hot mix asphalt with a WMA prepared using the foaming process technology. Both mixes contain $50 \%$ of RAP and are submitted to a laboratory ageing procedure. The long term related performance of the mixtures is compared by means of complex modulus and fatigue testing. Penetration and ring and ball tests are undertaken on the recovered bitumens, as well as the ageing evolution, characterised by the Fourier Transform Infrared analysis. Finally, the Apparent Molecular Weight Distribution (AMWD) of the binders is calculated from rheological measurements using the $\delta$-method. Results show a relation between ageing evolution and mechanical performance. After ageing, the overall tendencies are similar for both processes.
\end{abstract}

KEYWORDS: Durability; Rheology; Modulus of Elasticity; Fatigue; Modelization

Citation/Citar como: Perez-Martinez, M.; Marsac, P.; Gabet, T.; Pouget, S.; Hammoum, F. (2017) Ageing evolution of foamed warm mix asphalt combined with reclaimed asphalt pavement. Mater. Construcc. 67 [327], e125. http://dx.doi. org/10.3989/mc.2017.04716

RESUMEN: Evolución del envejecimiento en mezclas espumadas semicalientes con áridos reciclados. El comportamiento de mezclas asfálticas semicalientes (WMA) con alto contenido de material reciclado (RAP) es aún incierto a largo plazo. Por este motivo, en este estudio se compara el envejecimiento una mezcla caliente convencional y una mezcla espumada semicaliente con 50\% de RAP. Ambas mezclas han sido sometidas a un proceso de envejecimiento en laboratorio. La respuesta a largo plazo se ha comparado a través de los ensayos de módulo de rigidez y de fatiga. En los betunes recuperados se han llevado a cabo los ensayos de penetración y anillo-bola, así como el seguimiento del envejecimiento a través del análisis de infrarrojos. Finalmente, la distribución de peso molecular aparente (AMWD) de los betunes se ha calculado a través de medidas reológicas usando el " $\delta$-method". En los resultados se observa una relación entre la evolución del envejecimiento y su respuesta mecánica, donde la tendencia general es similar para ambas técnicas.

PALABRAS CLAVE: Durabilidad; Reología; Modulo Elástico; Fatiga; Modelización

ORCID ID: M. Perez-Martinez (http://orcid.org/0000-0002-8194-768X); P. Marsac (http://orcid.org/0000-00029021-7419); T. Gabet (http://orcid.org/0000-0003-4202-3609); S. Pouget (http://orcid.org/0000-0003-3857-6569); F. Hammoum (http://orcid.org/0000-0001-8449-9707)

Copyright: (C) 2017 CSIC. This is an open-access article distributed under the terms of the Creative Commons Attribution License (CC BY) Spain 3.0.

\section{INTRODUCTION}

The reduction of the manufacturing temperature of asphalt mixtures and the re-use of materials from old pavements, usually classified as solid waste disposals, present numerous advantages compared with traditional hot mix asphalts (HMA). The use of warm mix asphalt (WMA) and reclaimed asphalt pavement (RAP) separately are not new concepts, however innovation related to their combined 
application and performance has increased their use. Both techniques present their own benefits and drawbacks $(1,2)$, concerning durability issues, rutting or low temperature resistance that could be compromised during their service life. There are many environmental advantages associated with using these techniques including reduction in fuel consumption and greenhouse gas emissions, reduced extraction of natural aggregates and disposal of old asphalt (2-5).

The same processes that reduce energy consumption and improve workability in WMA technologies also allow them to act as compaction agents $(6,7)$. These improvements on compaction and densities achieved in situ tend to reduce permeability and bitumen ageing, which generally results in better performance of the blends in terms of crack resistance and moisture sensitivity (7).

From a study of all warm mix technologies, three main groups can be distinguished, namely: the foaming process, the use of organic additives and the use of chemical additives (7-10). The foaming effect which can be direct or indirect is created due to the contact of the water with the hot bitumen, increasing its volume and decreasing its viscosity. Organic additives are based on the addition of different types of waxes while chemical additives generally include a combination of emulsifying agents, surfactants and additives to improve workability and compaction of the mixture.

In a road, pavement removal and disposal is required at the end of its service life. RAP is the primary recycled material produced as a consequence of this process (2). Asphalt mixture crushing is carried out by milling machines that turn the existing mixture into different size particles to produce RAP. European Asphalt Paving Association (EAPA) data from 2014 shows that 50.2 million tonnes of RAP was produced in Europe (data from 25 countries) with 68.7 million tonnes produced in USA, thus encouraging its use as an alternative to virgin aggregates.

In addition, RAP fulfils the requirements for a sustainable pavement solution by presenting material cost savings while reducing the environmental impact of the asphalt manufacturing stage by $23 \%$ $(11,13)$. RAP is considered a stiff material due to the aged bitumen, which can promote unexpected failures depending on its the percentage content in the new mixture (12). Several authors have investigated the different stages of ageing of the asphalt binder during the mix manufacture and the pavement service life (14-17). Two phases can be distinguished: short term and long term ageing. Short term ageing takes places during manufacturing and construction of the road, and leads to an increase in bitumen viscosity. Meanwhile, long term ageing depends on the time of service and is related to progressive ageing by various mechanisms. Both types of ageing are associated with oxidation, evaporation of lighter components, thixotropy and syneresis, polymerization through chemical reaction of molecular components and components separation through the absorption of oily constituents by some type of aggregates $(15,17)$.

The current knowledge on ageing is essentially gained from practical experience on traditional asphalt mixes and typically on HMA. However, the road industry has embraced recycling and developed new techniques, particularly with WMA in order to limit its environmental impacts.

Consequently, and within this framework, the objective of the present work is to study and compare the foamed asphalt technique for WMA production when $50 \%$ of RAP is added to the mixture. This study is focused on comparison of the mechanical related performance of the mixtures and its bitumen evolution. Therefore, an ageing protocol is followed within the lines proposed by the RILEM TC-ATB TG5, consisting of two separate ageing phases. Following this, the ageing effect is evaluated through an analysis of the Apparent Molecular Weight Distribution (AMWD) of the bitumens. This comparison is achieved by the application of the $\delta$-method, a new method recently developed at IFSTTAR (18), which allows the calculation of AMWD from rheological measurements on the extracted bitumens. Additionally, the potential of the $\delta$-method as a tool for recycling studies is assessed.

\section{MATERIALS AND METHODS}

\subsection{Materials}

\subsubsection{Bitumen}

The neat bitumen chosen for the manufacture of the reference HMA and the foamed WMA (FWMA) mixture was a conventional bitumen $35 / 50$ with 37 $1 / 10 \mathrm{~mm}$ penetration (EN 1426) and $53.8^{\circ} \mathrm{C}$ softening point (EN 1427). For the foam process, the foaming effect was produced by injecting $1.5 \%$ of water under pressure into the hot bitumen pipe during its introduction into the mixer.

\subsubsection{Reclaimed Asphalt Pavement}

The reclaimed asphalt pavement used for the modification of the mixtures came from the milling operation of an overaged asphalt concrete $\mathrm{AC} 10$ located on the fatigue carousel track at IFSTTAR Nantes, France (21). The original bitumen in the RAP was of the same type (35/50). The RAP was characterized to guarantee good homogeneity. In order to achieve a continuous gradation for the correct design of the new mixtures, the material was split by sieving in four granular fractions 
$(0 / 2,2 / 4,4 / 8$ and $8 / 12 \mathrm{~mm})(22)$. The penetration grade and softening point measured on the bitumen extracted from the RAP were $181 / 10 \mathrm{~mm}$ and $63^{\circ} \mathrm{C}$ respectively.

\subsubsection{Virgin aggregates}

Gneiss rock, the original aggregate of the RAP, was the virgin aggregate used for both coarse and fine fractions $(0 / 2,2 / 6$ and $6 / 10 \mathrm{~mm})$ in order to retain continuity between the grading curves.

\subsection{Mixture}

This study was carried out with the aim of reproducing the initial AC10 design. Figure 1 summarizes the grading curves and design of the mixtures. For all the mixtures a constant bitumen content of $5.39 \%$ (22) was selected. A MLPC BBMAX 80 was used as mixer. The working sequence lasted for 75 seconds, with 15 seconds for the aggregates and fines mixing (and RAP when used) plus 60 seconds after the addition of the bitumen. RAP was preheated for $2 \mathrm{~h}$ at $110^{\circ} \mathrm{C}$ before manufacture, whereas virgin aggregates were heated at different temperatures depending on the type of mixture as shown in Table 1.

\subsection{Ageing procedure}

The purpose of this ageing step was to characterise, in laboratory conditions, the ageing experienced by the mixtures during road construction and their service life. This procedure was applied to 4 of the 8 mixtures manufactured. The ageing protocol carried out was based on the one proposed by the RILEM Technical Committee ATB TG5 (23) which forms the basis of norm (PR EN 12697-52: Conditioning to address oxidative ageing). It consisted of two phases of oxidative thermal ageing on asphalt mixtures, a short term phase simulating the manufacturing and construction phase of the road and a long term ageing that reproduces the end of life of the pavement. The short term ageing was performed after manufacture of the loose mix, and involved

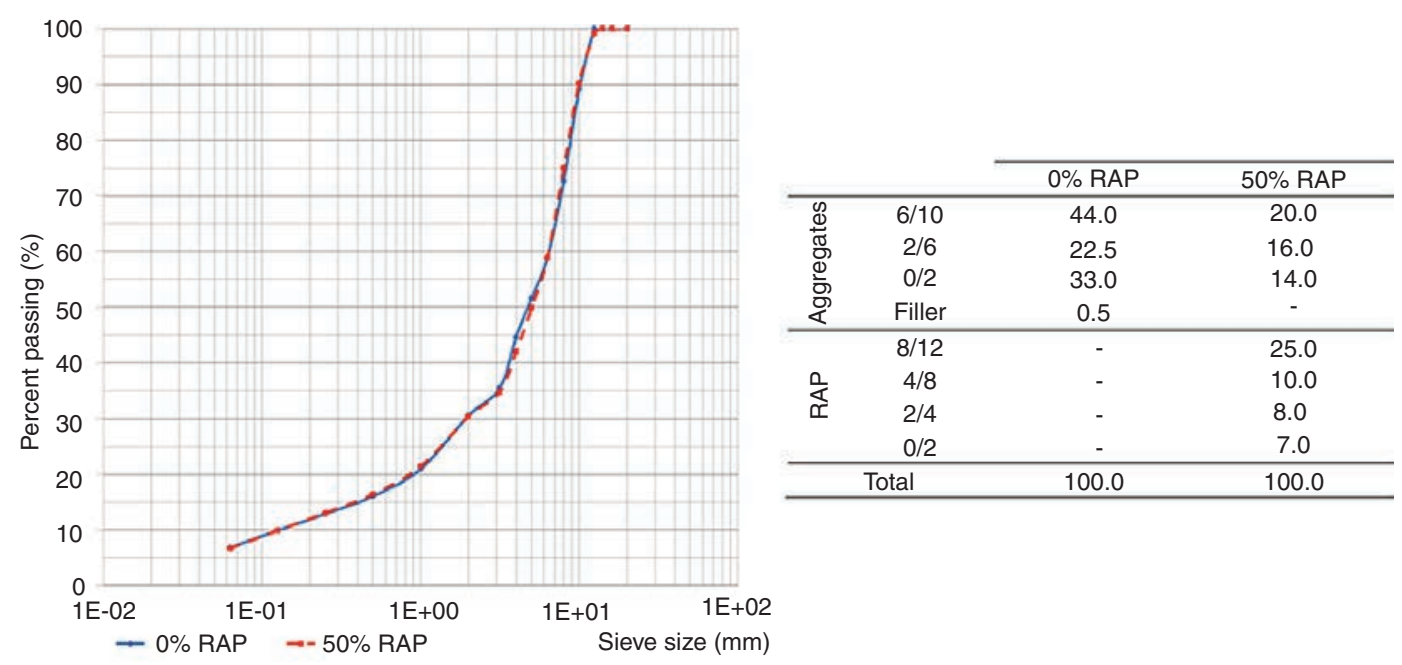

FIgURE 1. Mixtures gradations with and without RAP.

TABLE 1. Mixtures studied and manufacturing temperature

\begin{tabular}{|c|c|c|c|c|c|c|}
\hline Mixture & $\begin{array}{c}\text { Bitumen } \\
\text { Denomination } \\
\end{array}$ & $\%$ RAP & $\begin{array}{c}\text { Aggregates } \\
\left({ }^{\circ} \mathbf{C}\right)\end{array}$ & $\begin{array}{l}\text { RAP } \\
\left({ }^{\circ} \mathbf{C}\right)\end{array}$ & $\begin{array}{c}\text { Manufacture } \\
\left({ }^{\circ} \mathbf{C}\right)\end{array}$ & $\begin{array}{c}\text { Ageing } \\
\text { Procedure }\end{array}$ \\
\hline \multirow[t]{4}{*}{ Hot Mix Asphalt } & HMA0 & \multirow{2}{*}{0} & \multirow{2}{*}{160} & \multirow{2}{*}{-} & \multirow{2}{*}{160} & - \\
\hline & HMA0a & & & & & $\checkmark$ \\
\hline & HMA50 & \multirow{2}{*}{50} & \multirow{2}{*}{210} & \multirow{2}{*}{110} & \multirow{2}{*}{160} & - \\
\hline & HMA50a & & & & & $\checkmark$ \\
\hline \multirow{4}{*}{$\begin{array}{l}\text { Foamed Warm } \\
\text { Mix Asphalt }\end{array}$} & FWMA0 & \multirow{2}{*}{0} & \multirow{2}{*}{130} & \multirow{2}{*}{-} & \multirow{2}{*}{130} & - \\
\hline & FWMA0a & & & & & $\checkmark$ \\
\hline & FWMA50 & \multirow{2}{*}{50} & \multirow{2}{*}{150} & \multirow{2}{*}{110} & \multirow{2}{*}{130} & - \\
\hline & FWMA50a & & & & & $\checkmark$ \\
\hline
\end{tabular}

Bitumen always at $160^{\circ} \mathrm{C}$ 
heating the mix at $135^{\circ} \mathrm{C}$ for $4 \mathrm{~h}$ prior to compaction. Following this, the long term ageing process required holding the mixtures for 9 days at $85^{\circ} \mathrm{C}$ in a ventilated oven. This step was performed on compacted samples. Figure 2 illustrates the manufacturing procedure followed and the testing carried out.

\subsection{Testing}

\subsubsection{Tests on mixtures}

In total 8 mixtures were tested.

\section{Complex modulus}

To study the rheological and stiffness evolution of the mixtures, the complex modulus was measured according to EN 12697-26, Annex A (two point bending on trapezoidal specimens) between $1 \mathrm{~Hz}$ and $40 \mathrm{~Hz}$, and from $-10^{\circ} \mathrm{C}$ to $40^{\circ} \mathrm{C}$. In all cases, four samples were tested for each mixture.

\section{Fatigue resistance}

The resistance to fatigue was determined according to EN 12697-24, Annex A (two point bending on trapezoidal specimens) at $25 \mathrm{~Hz}$ and $10^{\circ} \mathrm{C}$ in strain controlled mode. By convention, the fatigue life of a specimen is equal to the number of loading cycles needed to decrease the specimen's stiffness modulus by $50 \%$. Three different strain amplitude levels were selected and generally 6 specimens were tested for each level. The fatigue law curves were fitted on the experimental points by linear regression in a log-log diagram of number of cycles by strain level. In order to compare the value of $\varepsilon_{6}$ under the same air voids content $(\mathrm{C})$, the formula $\Delta \varepsilon_{6}(\mu \mathrm{def})=3.3 \cdot \Delta \mathrm{C}(\%)(26)$ was used to correct the results. This formula allows the value of $\varepsilon_{6}$ at $4.5 \%$ of voids to be evaluated.

\subsubsection{Tests on bitumens}

After the 8 mixtures were manufactured and the ageing protocols applied, bitumens were extracted and recovered using the rotary evaporator for bitumen recovery following the EN 12697-3 standard. The aged bitumen from the RAP (35/50 RAP) was also recovered under the same procedure. Additionally, with the $35 / 50$ Neat and the $35 / 50$ Foam, a total of 11 bitumen samples were tested.

\section{Standard consistency tests}

The standard consistency of the bitumens was characterized by the penetration depth $(1 / 10 \mathrm{~mm})$ (EN 1426) and the temperature of the softening point $\left({ }^{\circ} \mathrm{C}\right)(\mathrm{EN} 1427)$.

\section{Fourier Transform Infrared (FTIR) analysis}

The Fourier Transform Infrared (FTIR) analysis was performed with the purpose of monitoring the ageing of the binders. The FTIR test consists of exciting the material with infrared light and then quantifying the different types of molecular bonds through characteristic absorption bands in the transmitted infrared light spectrum. Carbonyl groups (esters, ketones etc.) characterised by $\mathrm{C}=\mathrm{O}$

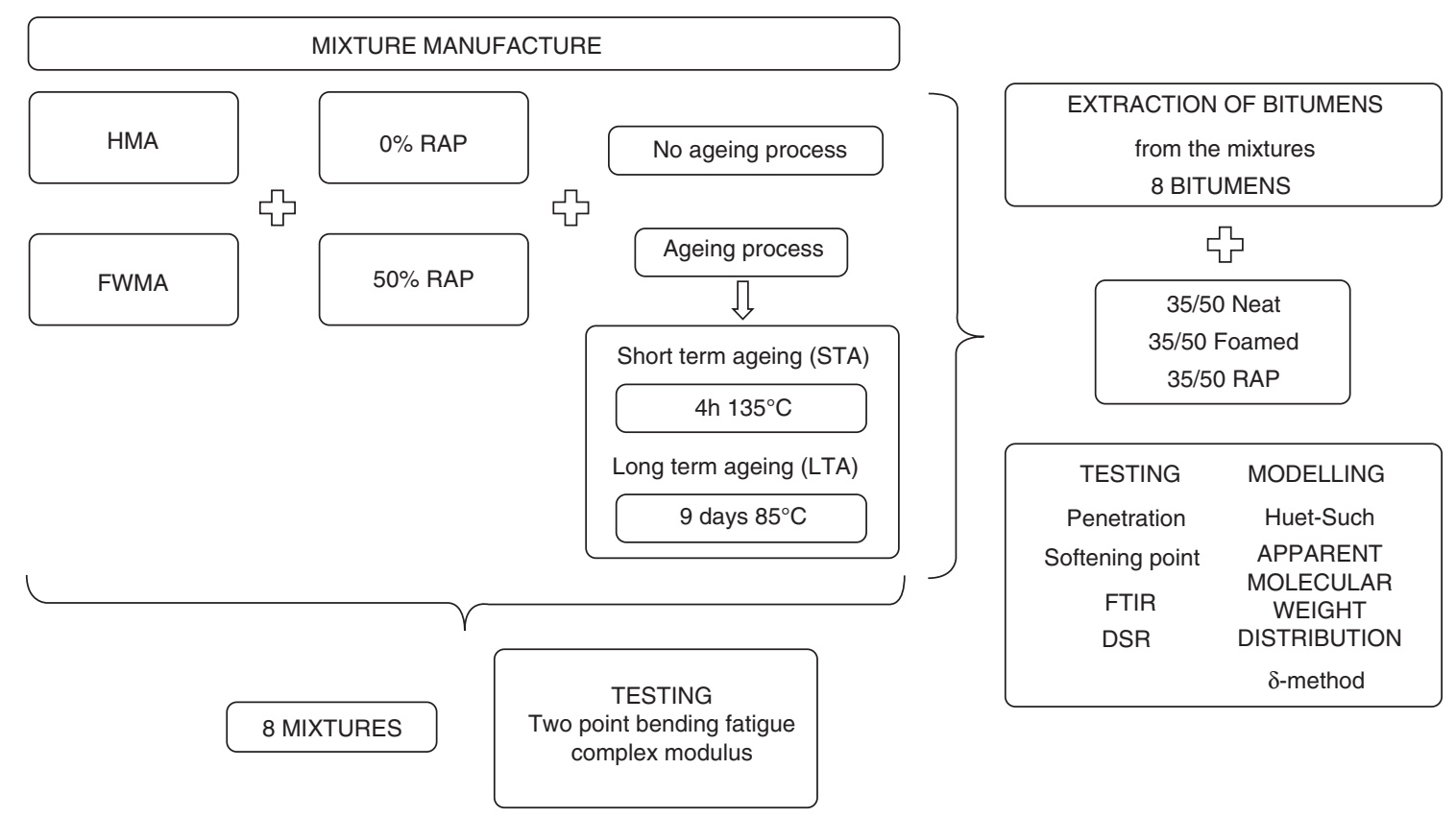

FIGURE 2. Manufacturing process for mixtures testing and bitumen extraction. 
double bonds are among the major functional groups formed during oxidative ageing (28) and it was demonstrated that their formation changes the physical properties of the binder in a predictable way (29). The carbonyl index, ICo, was calculated from the raw FTIR spectra according to the RILEM method (30). The limits on the spectra for carbonyl compounds were between 1.660 and $1.753 \mathrm{~cm}^{-1}$, while the reference area was between 1.350 and $1.525 \mathrm{~cm}^{-1}$.

\section{Complex shear modulus test}

The determination of the complex shear modulus and phase angle was performed using the dynamic shear rheometer Kinexus ${ }^{\circledR}$ to assess the rheological properties of the bitumens. The complex shear modulus $\left(\mathrm{G}^{*}\right)$ was obtained by combining the measurements performed on annular shearing geometries of parallel plates of $25 \mathrm{~mm}$ and $8 \mathrm{~mm}$ from $20^{\circ} \mathrm{C}$ to $60^{\circ} \mathrm{C}$ and $-20^{\circ} \mathrm{C}$ to $20^{\circ} \mathrm{C}$ respectively, and at a frequency range from 1 to $25 \mathrm{~Hz}$. The conversion from $\mathrm{G}^{*}$ to $\mathrm{E}^{*}$ was made assuming a Poisson's ratio of 0.5 for almost incompressible behaviour (31).

\subsection{Modelling}

A rheological model was fitted on the experimental points in order to get a comprehensive overview of the trends for the complex shear modulus and to overcome the processing problems induced by the large amount of data (for each bitumen sample there are approximately 70 values for the norm $\left|\mathrm{E}^{*}\right|$ and the phase angle $\delta$ ). This is carried out to concentrate the information of the frequency and temperature sweeps in a limited number of model parameters describing the properties of the binder in the complete time-temperature domain.

Several studies carried out in different countries demonstrated that the Huet-Such model was one of the best suited rheological models for bitumen. This model is a combination of one spring, two parabolic creep elements and one dashpot all placed in series with a coefficient that regulates the balance between the two parabolic elements (Figure 3). The 6 model parameters were determined by fitting the experimental complex modulus data $\left|\mathrm{E}^{*}\right|$ and $\delta$ measured at different frequencies and temperatures. The $\tau$ parameter was determined for a reference temperature $\mathrm{T}_{\text {ref }}=0^{\circ} \mathrm{C}$.

\subsection{Molecular weight distribution ( $\delta$-method)}

It has been generally assumed that Molecular Weight Distribution (MWD) of bitumen and its rheological properties are related (32-36). Themeli's work in 2015 considered that the phase angle $(\delta)$ of the complex modulus for a given frequency is proportional to the fraction of relaxed molecules at this frequency. It considered the material as a combination of monodispersed molecular weight (MW) species, so therefore, a relationship between the oscillation frequency and the molecular weight of the material could be established (18). From vapour pressure osmometry measurements, Zanzotto established a relationship between the crossover frequencies $(\omega(\mathrm{co})$, i.e. storage modulus equal to loss modulus) at a temperature $\mathrm{T}=0^{\circ} \mathrm{C}$ and the $\mathrm{MW}$ (36), defined by the formula [1]:

$$
\log (\mathrm{MW})=2.880-0.06768 \cdot \log (\omega)
$$

When this equation is applied to the frequency axis of the phase angle master curve, it can be plotted as a function of the MW. Considering the hypothesis that the cumulative molecular weight distribution, cumf, is proportional to the phase angle master curve, the formula that relates both can be obtained [2]:

$$
\operatorname{cumf}(\mathrm{MW})=\mathrm{A}+\mathrm{B} \cdot \delta(\mathrm{MW})
$$

where $f$ is a differential distribution, $A$ and $B$ are the proportionality constants which are calculated from the boundary conditions:

$$
\begin{array}{lll}
\text { for } M W \rightarrow 0 & \delta(M W)=0^{\circ} & \operatorname{cumf}(M W)=0 \\
\text { for } M W \rightarrow \infty & \delta(M W)=90^{\circ} & \operatorname{cumf}(M W)=1
\end{array}
$$

As a result of the calculus, $A=0$ and $B=1 /\left(90^{\circ}\right)$.

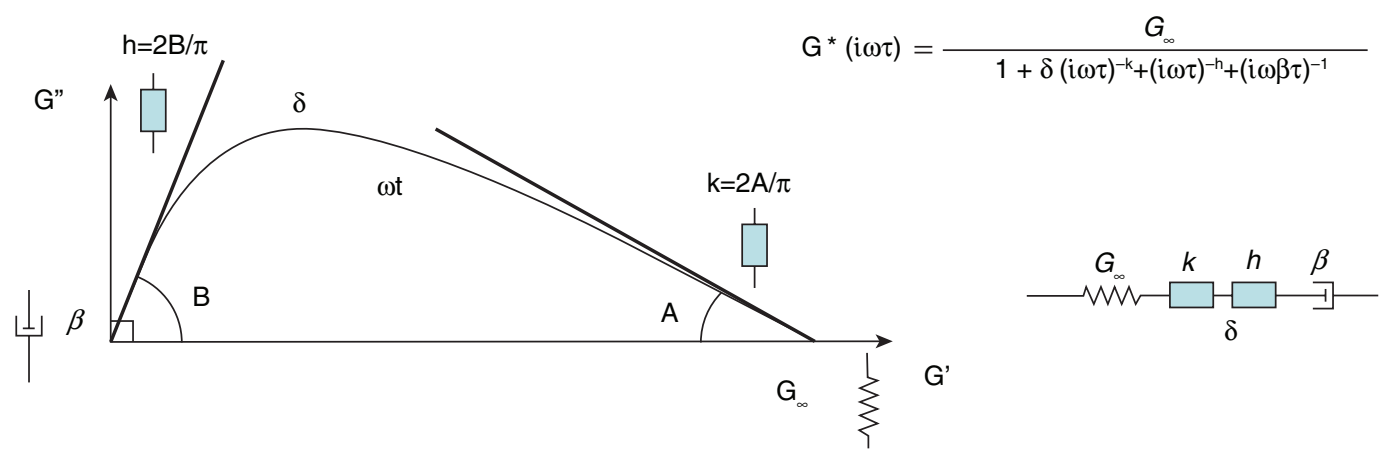

Figure 3. Huet-Such model, equation and Cole-Cole representation. 
If this last formula [2] is differentiated, the differential molecular weight distribution (DMWD) can be calculated (18). The differentiation can be obtained numerically according to the equation [3]:

$$
f(M W)=\frac{\operatorname{dcumf}(M W)}{\operatorname{dlog} M W} \cong \frac{\operatorname{cumf}(M W)}{\log M W}
$$

This differentiation requires a continuous curve, so the data from DSR measurements must be fitted with a continuous model. The Huet-Such model parameters fitted as described in $\$ 2.4$ are used for this purpose.

The numerical differentiation was carried out applying a numerical differential step of $1 / 3,000$ to the $\log (M W)$ in order to achieve the convergence. The MWD is termed "apparent" because the proportionality to the phase angle, proved for polymers, is assumed for bitumen in this study. This assumption is still to be confirmed. The word "apparent" is also used because the $\delta$-method appears to capture the effect of groups of molecules (like clusters of asphaltenes) and not only individual molecules.

\section{ANALYSIS OF RESULTS}

\subsection{Mixture testing}

The results obtained for the dynamic complex modulus and the fatigue resistance are presented in Table 2 with the norm of the complex modulus at $15^{\circ} \mathrm{C}$ and $10 \mathrm{~Hz}$. Additionally the values of $\varepsilon_{6}$ (strain level at 1,000,000 cycles) obtained and corrected to the target air voids of $4.5 \%$ are also indicated. Figure 4 illustrates the differences with ageing, the use of RAP and the technique employed.

\subsubsection{Complex modulus}

The trends obtained for the complex modulus in all mixtures seem realistic, being in all cases the material stiffer after applying the ageing protocol or when RAP was added (37). Considering now only the mixtures before ageing and without RAP, the

TABLE 2. Dynamic complex modulus and fatigue resistance results

\begin{tabular}{lccccc}
\hline Mixtures & $\begin{array}{c}\left|\mathbf{E}^{*}\right| \mathbf{1 5}{ }^{\circ} \mathbf{C}, \\
\mathbf{1 0 H z}_{(\mathbf{M P a})}\end{array}$ & $\begin{array}{c}\text { Phase } \\
\text { Angle }\left({ }^{\circ}\right)\end{array}$ & $\begin{array}{c}\boldsymbol{\varepsilon}_{\mathbf{6}} \\
(\boldsymbol{\mu d e f})\end{array}$ & $\begin{array}{c}\text { Corrected } \boldsymbol{\varepsilon}_{\mathbf{6}} \\
(\boldsymbol{\mu d e f})\end{array}$ & $\begin{array}{c}\text { Slope } \\
(-\mathbf{- 1 / b})\end{array}$ \\
\hline HMA0 & 12,497 & 15.0 & 118 & 115 & 5.99 \\
HMA0a & 14,156 & 10.8 & 123 & 123 & 8.35 \\
HMA50 & 14,590 & 12.2 & 132 & 127 & 7.08 \\
HMA50a & 15,847 & 11.3 & 128 & 122 & 6.99 \\
FWMA0 & 10,921 & 16.1 & 92 & 91 & 2.79 \\
FWMA0a & 14,448 & 12.2 & 113 & 111 & 9.00 \\
FWMA50 & 13,122 & 14.0 & 108 & 105 & 5.06 \\
FWMA50a & 15,460 & 11.5 & 120 & 113 & 7.08 \\
\hline
\end{tabular}

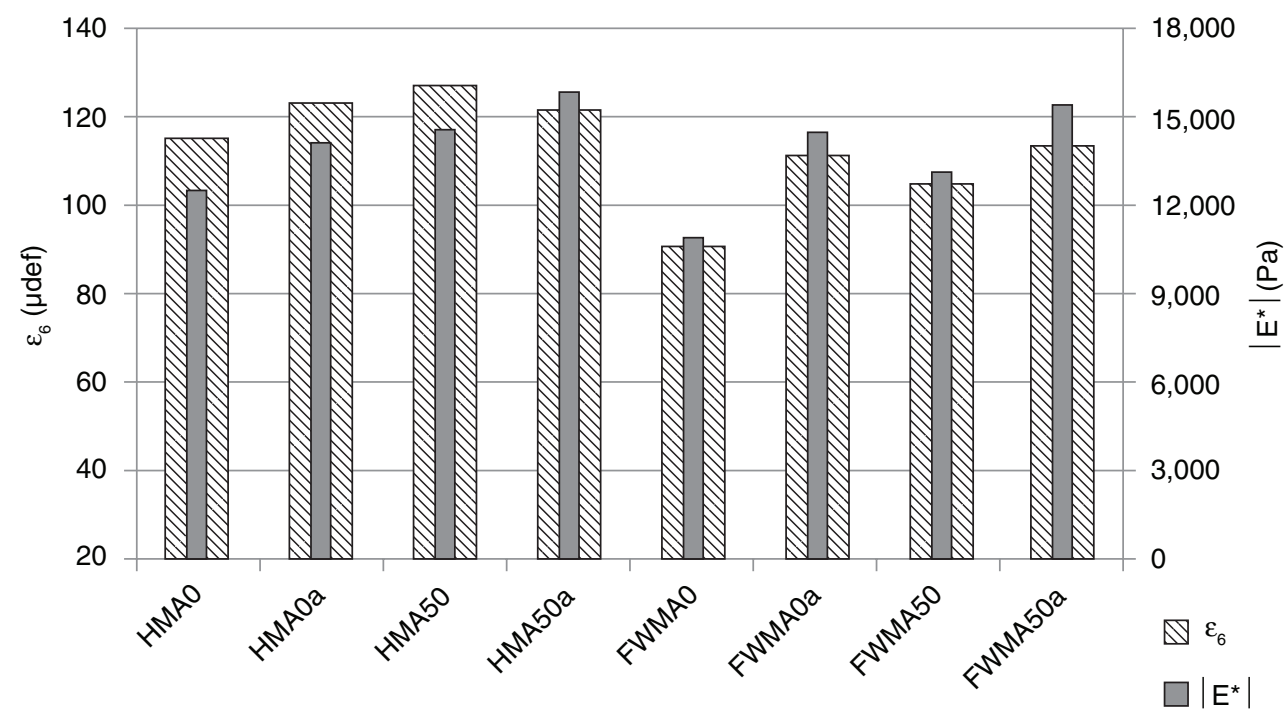

FIGURE 4. Differences between mixtures with respect to ageing, RAP or technique. 
results show that the FWMA0 mixture has a stiffness modulus $13 \%$ lower than the HMA0, but still over the 7,000 MPa requested by the standards (EN 13108-1). In the case of the mixtures with RAP, FWMA50 has a modulus only $10 \%$ lower than HMA50.

\subsubsection{Fatigue resistance}

Figure 5 and Figure 6 show the fatigue laws of the mixtures, separated by procedure of manufacture, HMA and FWMA, and compared in pairs by ageing state and RAP content. The increment shown by the $\varepsilon_{6}$ parameter when RAP is added or after ageing seems to be linked to an increment on the slope $(-1 / b)$ of the fatigue law.
Figure 5 illustrates the similarities on fatigue performance for all the HMA mixtures. The increment of the slope observed with RAP addition or ageing is more pronounced on the foaming process. This could be due to the compensation of a lesser ageing during the manufacturing process (as the foam mixture was manufactured at $130^{\circ} \mathrm{C}$ ) by a stronger effect of the ageing process. In general, when ageing takes place the fatigue slope increases, and consequently the fatigue resistance of the material tends to be more sensitive to the strain level. Moreover, the influence of RAP addition can be observed in the last column of graphs in Figure 5. Similarly to ageing, when RAP is added the fatigue slope increases.

From Figure 6, the results obtained for the mixtures HMA and FWMA without RAP show that
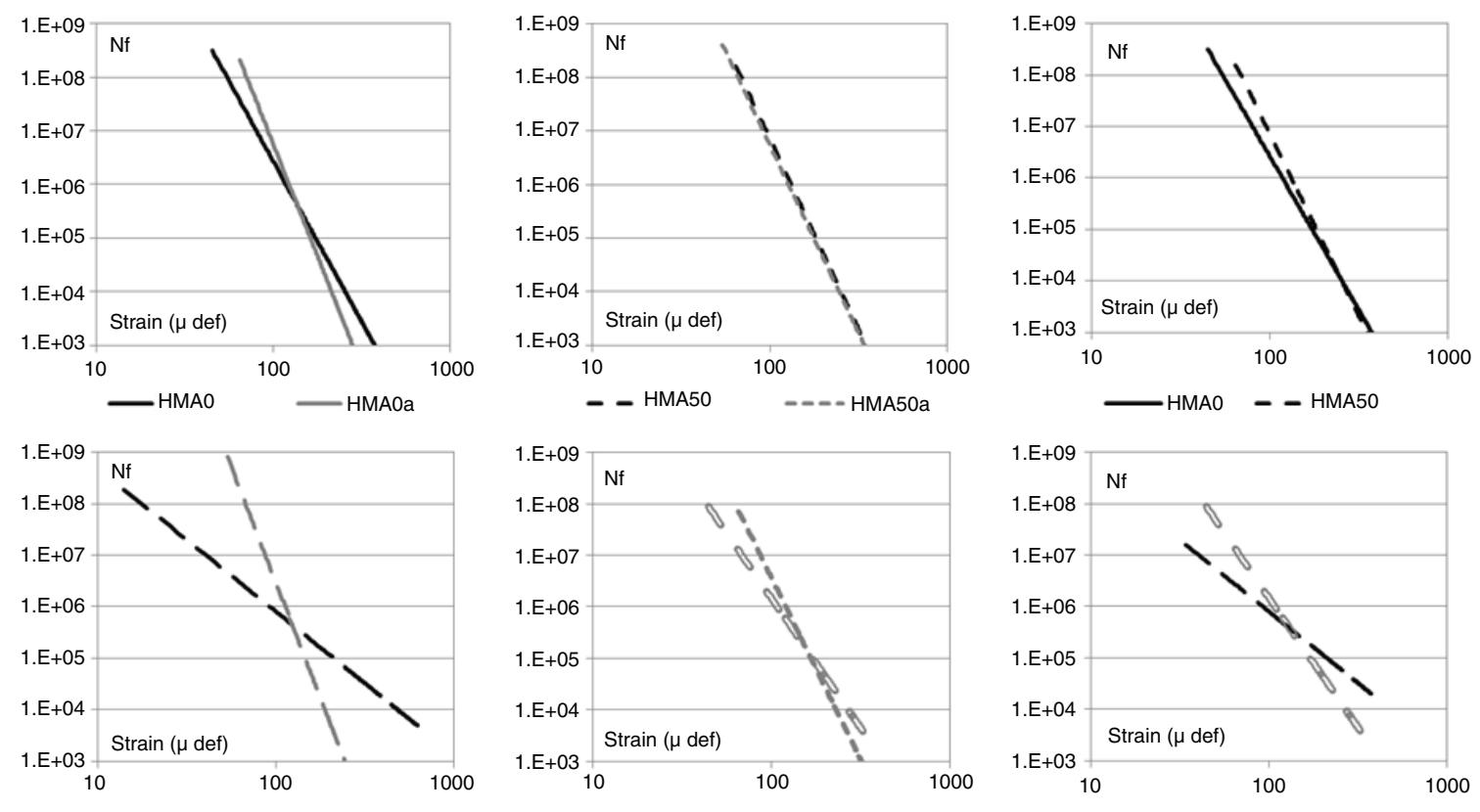

- - FWMAO - -FWMAOa

๑FWMA50 - - FWMA50a

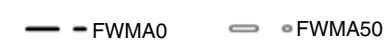

FIGURE 5. Fatigue laws of all mixtures by ageing state and RAP content.
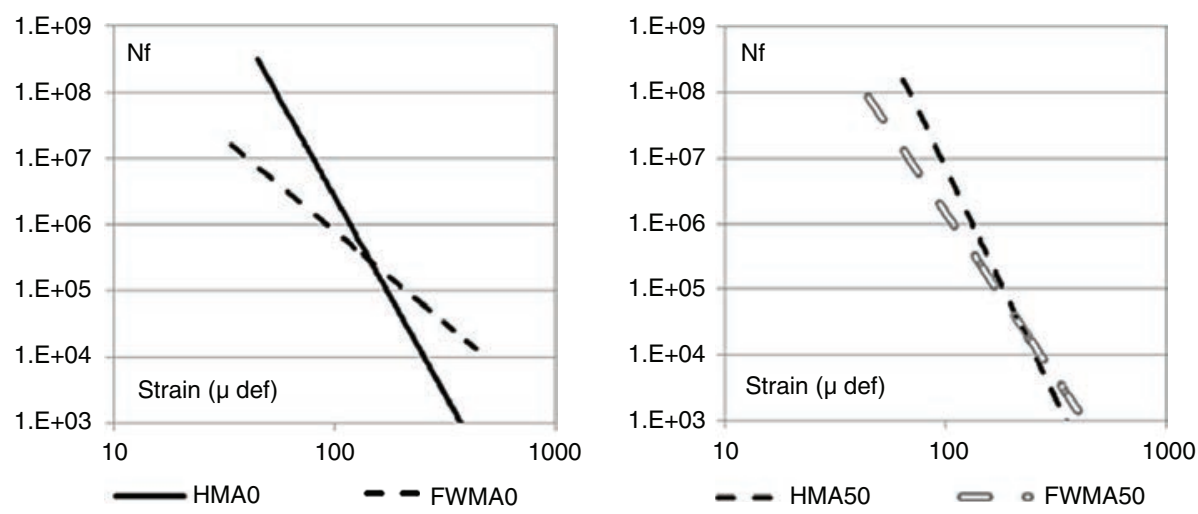

FIGURE 6. Fatigue laws by manufacture procedure and RAP effect. 
not only the value of $\varepsilon_{6}$ should be considered when comparing the performance, but also the increment of slope is important as the fatigue life is dependent on the strain level.

\subsection{Bitumen testing}

Table 3 summarizes the penetration, softening point and carbonyl index results.

\subsubsection{Penetration}

Figure 7 shows the penetration values obtained by manufacture procedure and ageing effect. The usual high temperature manufacturing process induces a drastic decrease of the binder penetration value, by $40 \%$ for HMA0 (37 to $221 / 10 \mathrm{~mm}$ ), compared to the foaming process, only 14\% for FWMA0 (37 to 32 $1 / 10 \mathrm{~mm})$. After ageing, the penetration values tend to reach similar values for the 2 techniques (15 1/10 $\mathrm{mm}$ for HMA0a and 18 1/10 mm for FWMA0a). The bitumen penetration decreases mainly during the manufacturing process for the HMA whereas ageing leads the changes on the FWMA mixture.

TABLE 3. Penetration, softening point and FTIR results

\begin{tabular}{lccc}
\hline Bitumen & $\begin{array}{c}\text { Penetration } \\
\mathbf{1 / 1 0 ~} \mathbf{~ m m}\end{array}$ & $\begin{array}{c}\text { Softening Point } \\
\left({ }^{\circ} \mathbf{C}\right)\end{array}$ & ICo \\
\hline 35/50 Neat & 37 & 53.8 & 0.00 \\
35/50 RAP & 18 & 63.0 & 8.60 \\
HMA0 & 22 & 55.0 & 1.80 \\
HMA0a & 15 & 65.8 & 4.96 \\
HMA50 & 19 & 62.8 & 4.08 \\
HMA50a & 15 & 66.0 & 8.27 \\
35/50 Foam & 34 & 53.6 & 0.00 \\
FWMA0 & 32 & 55.6 & 0.48 \\
FWMA0a & 18 & 63.8 & 5.40 \\
FWMA50 & 24 & 60.4 & 5.47 \\
FWMA50a & 17 & 66.0 & 10.35 \\
\hline
\end{tabular}

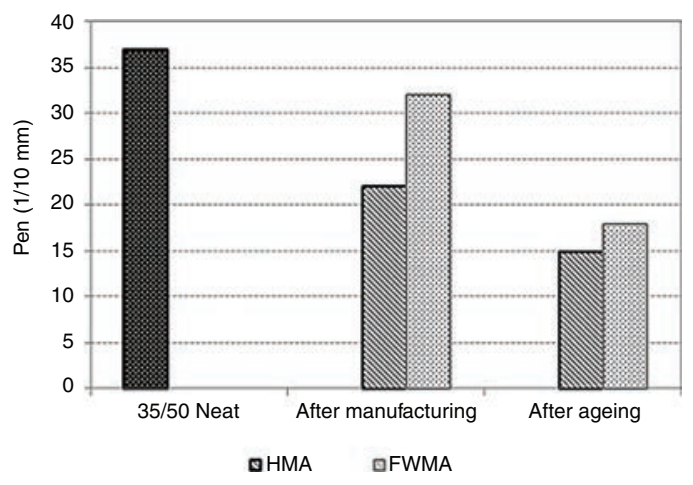

When RAP is added the initial binder penetration calculated with the blending law according to EN 13108-1 Annex A is $261 / 10 \mathrm{~mm}$. After manufacturing, the penetration decreases by $27 \%$ for the HMA50 and 8\% for the FWMA50. The penetration values also tend to reach similar values for the 2 manufacturing processes after ageing (15 1/10 mm for HMA50a and 17 1/10mm for FWMA50a). Mixtures with RAP show the same trends than mixtures without RAP but the amplitudes of variation are reduced. These observations clearly show that the high temperature manufacturing process induces a more pronounced hardening of the binder than the low temperature foaming process. They also show that penetration sensitivity to ageing seems to be roughly proportional to the penetration value suggesting an exponential decay law.

\subsubsection{Softening point}

The increase of the softening point during manufacturing is limited and similar for the 2 processes: $1.2^{\circ} \mathrm{C}$ for the HMA0 and $1.8^{\circ} \mathrm{C}$ for the FWMA0 bitumen. On the other hand, the increase is important after ageing: $10.8^{\circ} \mathrm{C}$ for the HMA0a and $8.2^{\circ} \mathrm{C}$ for the FWMA0a bitumen, as can be observed in Figure 8.

When RAP is added the bitumen softening point calculated with the blending law, according to EN 13108-1 Annex $\mathrm{A}$ is $58^{\circ} \mathrm{C}$. After the manufacturing process, the softening point increases by $4.1^{\circ} \mathrm{C}$ for the HMA50 and $2.4^{\circ} \mathrm{C}$ for the FWMA50. As observed for the mixtures without RAP, the softening point evolution is very limited for the two techniques. In both cases the increase after ageing is lower than for mixtures without RAP: $3.2^{\circ} \mathrm{C}$ for HMA50a and $5.6^{\circ} \mathrm{C}$ for FWMA50a.

Independently of the manufacture technique employed or the RAP content, the softening point tends to reach an asymptotic value between $64^{\circ} \mathrm{C}$ and $66^{\circ} \mathrm{C}$ after ageing. Contrary to what was observed for penetration, the effect of the manufacturing process is not evident on the softening point.

FIGURE 7. Penetration results by manufacture procedure and ageing effect. 
For all the mixtures, the main evolution of the softening point occurs during the ageing process.

\subsubsection{Carbonyl index}

Compared to the conventional procedure, the foaming process generates less carbonyl bonds for the mixtures without RAP, as Figure 9 illustrates. But in all other cases (after ageing, with RAP addition and after combining RAP and ageing), it generates more of these bonds. This could mean that the water injected in the bitumen for producing the foam may affect the oxidation process in a different way (26). In general the carbonyl bonds are mostly created during the ageing process. For mixtures with RAP, a weighted average is applied as mixing law to estimate the ICo of the 35/50 Neat and RAP binder blend before manufacture. For the next steps, this initial value acts like an offset, suggesting that the carbonyl bonds created in the neat binder during the manufacture and the ageing process gradually add up to an almost constant proportion of bonds initially existing in the RAP binder.

\subsection{Modelling}

The raw data obtained from testing the 35/50 Neat bitumen is represented in Figure 10 as an example of all the bitumen tested. It shows the values of

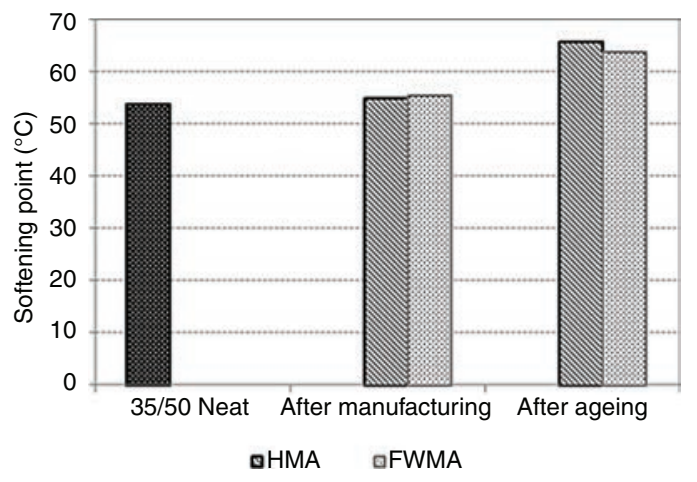

the norm of the complex modulus $\left|\mathrm{E}^{*}\right|(\mathrm{Pa})$ and phase angle $\delta\left(^{\circ}\right)$ as a function of the frequency $(\mathrm{Hz})$. Furthermore, the translation coefficients according to the temperature $\left(\mathrm{a}_{\mathrm{T}}\right)$ calculated by the WilliamLandel-Ferry adjustment (39) are presented along with the experimental points and the Huet-Such modelling in the Cole-Cole space.

For the different binders, $\left|\mathrm{E}^{*}\right|$ and phase angle master curves at $0^{\circ} \mathrm{C}$ are presented in Figure 11. It illustrates the evolution of the bitumen with ageing, showing that $\left|\mathrm{E}^{*}\right|$ values increase and the frequency range for a transition of the angle from $0^{\circ}$ to $90^{\circ}$ is extended.

Experimental data has been fitted by the HuetSuch rheological model and the 6 parameters $\left(\mathrm{E}_{\infty}\right.$, $\delta, \mathrm{k}, \mathrm{h}, \beta$ and $\tau$ ) obtained are shown in Table 4. Regardless the type of bitumen and the manufacturing technique employed the value of glassy modulus $\left(\mathrm{E}_{\infty}\right)$ remains almost constant around $1.9 \mathrm{GPa}$. Also, the first parabolic element $(\mathrm{k})$, proportional to the slope of the model in the Cole-Cole plan at low temperature and/or high frequency, remains stable at the average value of 0.24 . The value of the $\mathrm{h}$ parameter (proportional to the slope of the model in the Cole-Cole plan at high temperature and/or low frequency) decreases when the ageing protocol is applied. On the other hand the value of $\beta$ (viscosity at very high temperatures or very low frequencies) in general increases either when ageing occurs

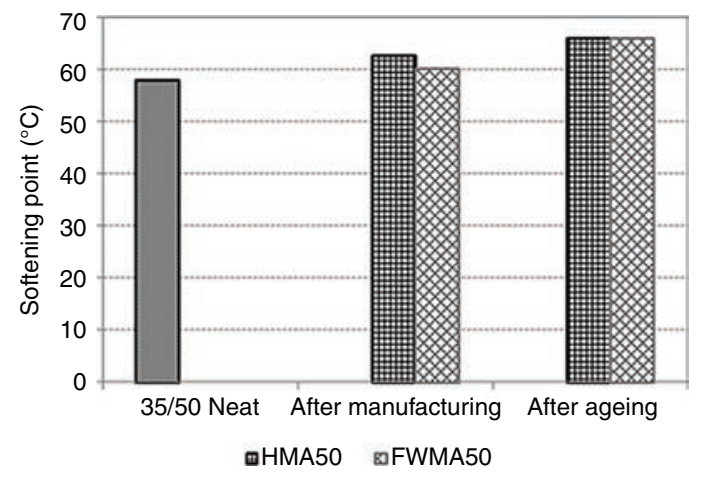

FIGURE 8. Softening point results by manufacture procedure and ageing effect.
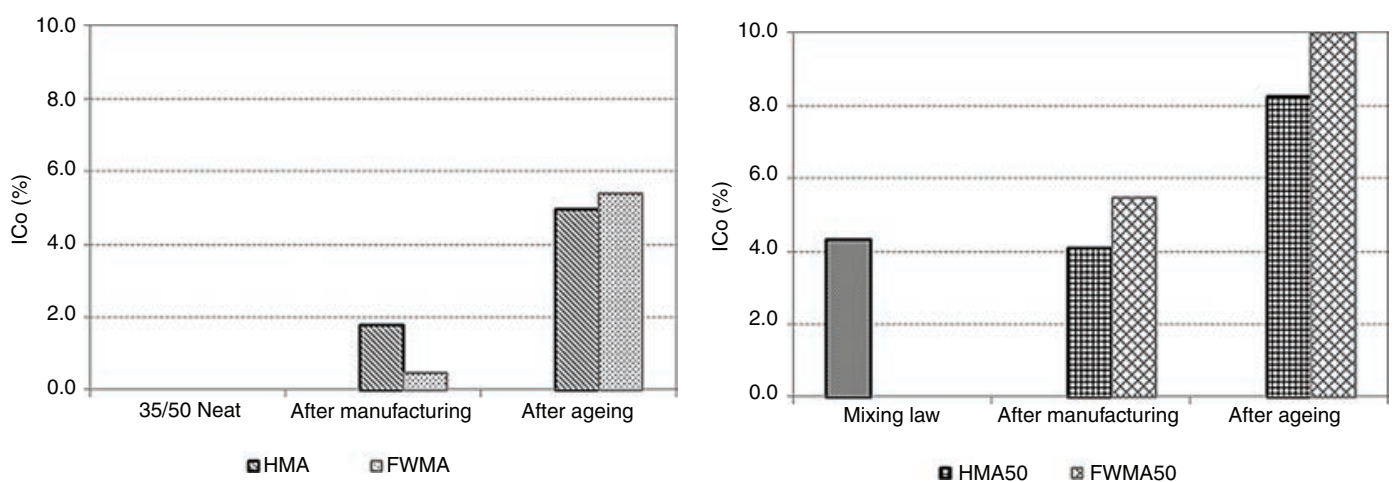

FIGURE 9. Index carbonyl results by manufacture procedure and ageing effect. 

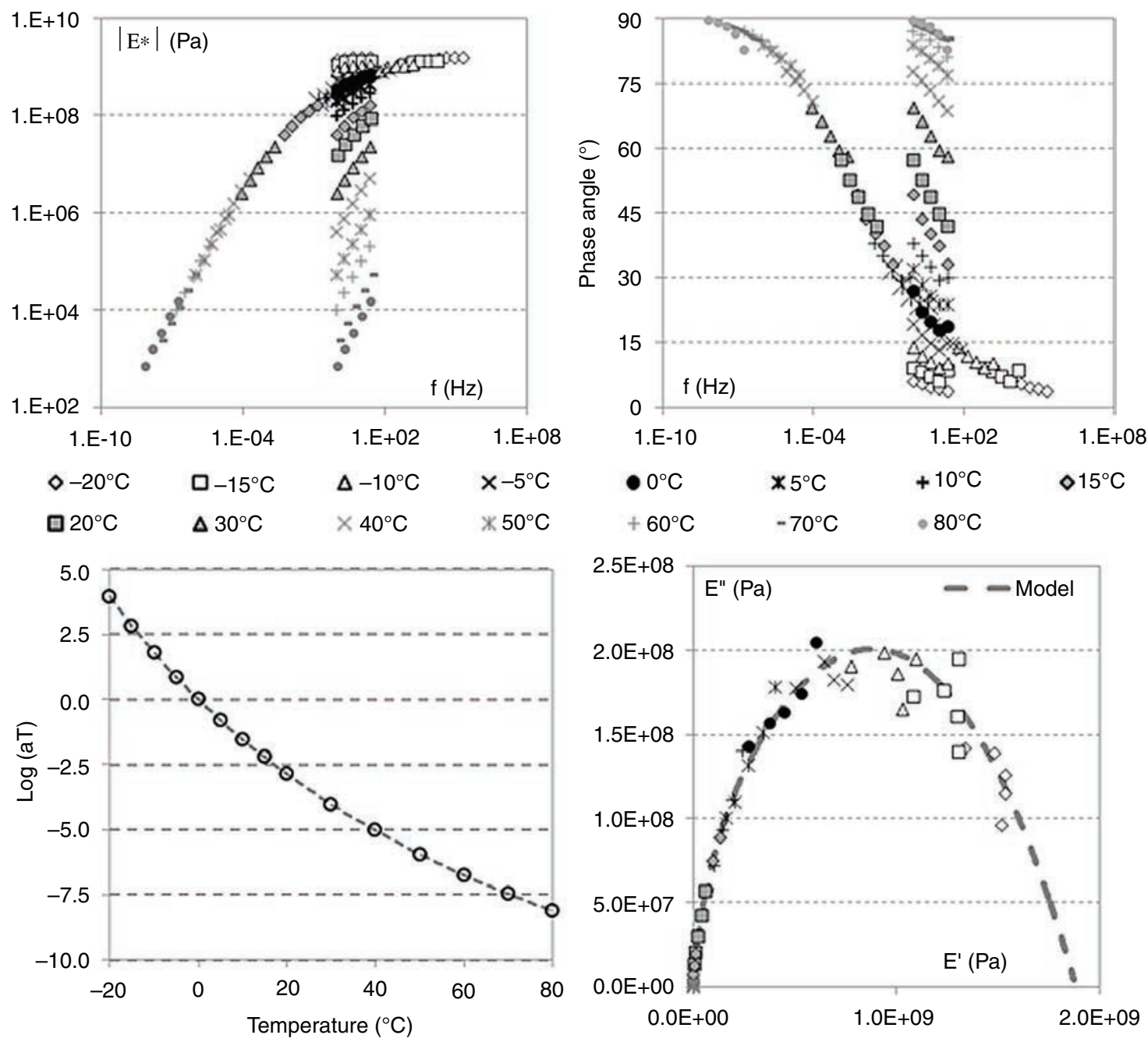

Figure 10. $35 / 50$ Neat bitumen master curves at $0^{\circ} \mathrm{C}, \mathrm{WLF}$ adjustment and Cole-Cole representation.
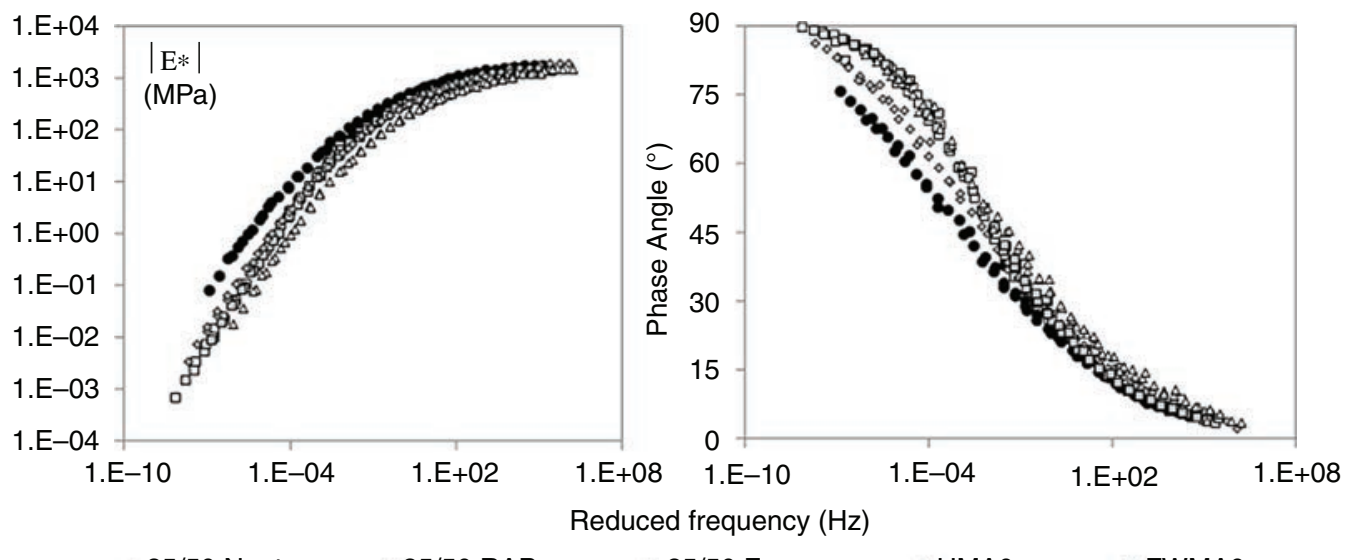

- 35/50 Neat

• 35/50 RAP

口 35/50 Foam

- HMAO

$\triangle$ FWMAO

FIGURE 11. Bitumen master curves at $0^{\circ} \mathrm{C}$. 
or RAP is added, as it happens with the frequency multiplier $\tau(\mathrm{s})$.

\subsection{Apparent molecular weight distribution ( $\delta$-method)}

The AMWD in the range between 100 and 10,000 $\mathrm{g} / \mathrm{mol}$ are presented in Figure 12, 13 and 14 with the ordinate axis corresponding to the probability density $\mathrm{f}(\mathrm{AMW})$. The cross-over frequency point $\omega(\mathrm{co})$ (i.e. storage modulus equal to loss modulus) is also plotted in the graphs. Ageing is presented as an increase of the concentration of high molecular weight molecules, creation of new peaks, and a shift of the distributions and the cross-over frequency points towards higher AMWs. These results are in accordance with the literature, where it is described that with ageing part of the oily fraction (mainly resins) seems to be absorbed by the asphaltenes and dispersed in the light matrix $(34,40)$ reorganizing its situation together into a colloidal system of molecules and producing some clustering as well.

In Figure 12, the AMWD of the base bitumens and the extracted binder from the first step of both procedures are compared. In the first case the results show a similar AMWD for the 35/50 Foam bitumen and the 35/50 Neat bitumen in comparison to the aged 35/50 RAP that has two differentiated populations with $1,000 \mathrm{~g} / \mathrm{mol}$ as a middle point. On the second graph, the AMWD of the FWMA0 bitumen presents lower ageing induced by the manufacturing process compared to the HMA0 bitumen and in line with the other results obtained. The AMWD drawn by the HMA0 bitumen tends toward the 35/50 RAP distribution.

Furthermore, in Figure 13 the AMWDs of the bitumens extracted from all the manufactured mixtures are presented by ageing state and RAP content. In all cases it can be observed that there is an increase of the concentration of high molecular weight molecules and the displacement of the right side of the distribution. Finally, in Figure 14, as described for the fatigue behaviour, AMWD of the bitumens before and after manufacture are presented. This step represents the changes induced during the manufacturing procedure. In the case of the HMA0 bitumen it not only shows a decrease of the fraction around $800-900 \mathrm{~g} / \mathrm{mol}$ (mainly saturates

TABLE 4. Huet-Such rheological model parameters

\begin{tabular}{lcccccc}
\hline $\begin{array}{l}\text { Bitumen/ } \\
\text { Parameter }\end{array}$ & $\mathbf{E} \boldsymbol{\infty}(\mathbf{M P a})$ & $\boldsymbol{\delta}$ & $\mathbf{k}$ & $\mathbf{h}$ & $\boldsymbol{\beta}$ & $\boldsymbol{\tau}(\mathbf{s})$ \\
\hline 35/50 Neat & 1,885 & 4.12 & 0.26 & 0.66 & 38.09 & $1.54 \mathrm{E}-01$ \\
35/50 RAP & 2,122 & 3.76 & 0.23 & 0.59 & 367.97 & $1.77 \mathrm{E}-01$ \\
HMA0 & 2,074 & 4.69 & 0.26 & 0.64 & 164.02 & $4.57 \mathrm{E}-01$ \\
HMA0a & 1,952 & 4.39 & 0.24 & 0.59 & 626.02 & $4.00 \mathrm{E}-01$ \\
HMA50 & 1,978 & 5.52 & 0.25 & 0.65 & 214.01 & $1.24 \mathrm{E}+00$ \\
HMA50a & 1,939 & 5.35 & 0.24 & 0.62 & 171.17 & $9.43 \mathrm{E}-01$ \\
35/50 Foam & 1,708 & 3.65 & 0.24 & 0.63 & 45.80 & $1.07 \mathrm{E}-01$ \\
FWMA0 & 1,681 & 4.82 & 0.27 & 0.64 & 67.86 & $1.96 \mathrm{E}-01$ \\
FWMA0a & 1,832 & 5.33 & 0.24 & 0.60 & 191.94 & $5.08 \mathrm{E}-01$ \\
FWMA50 & 1,972 & 4.50 & 0.26 & 0.64 & 129.65 & $2.07 \mathrm{E}-01$ \\
FWMA50a & 1,802 & 6.82 & 0.27 & 0.63 & 158.47 & $8.15 \mathrm{E}-01$ \\
\hline
\end{tabular}
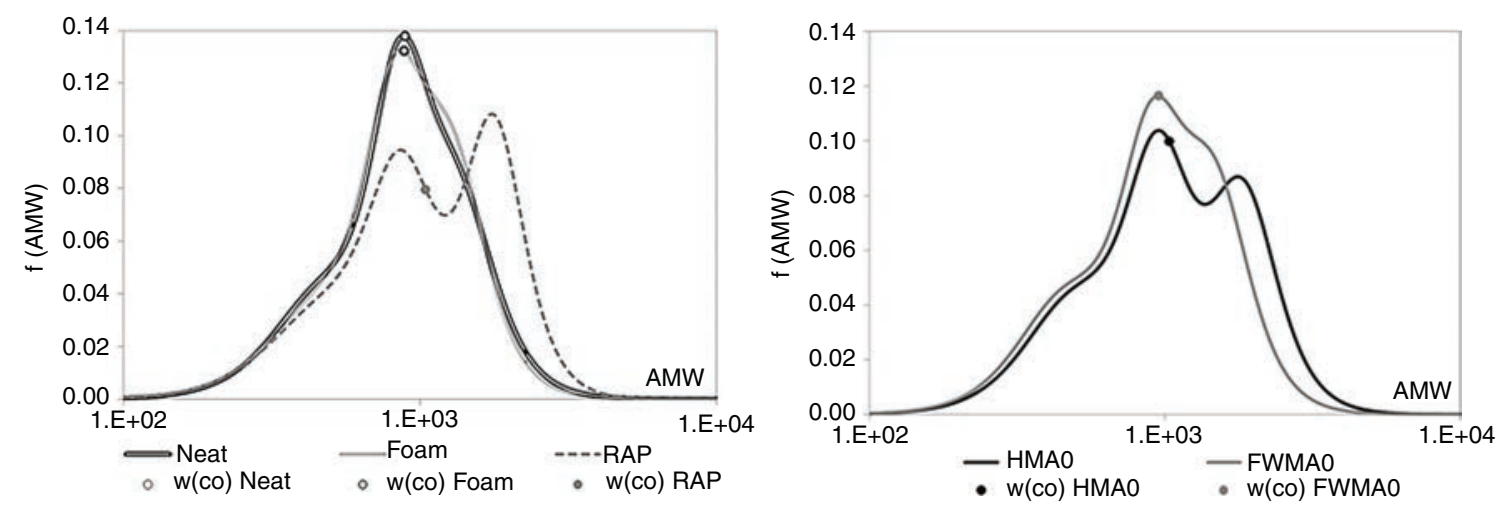

FIGURE 12. AMWD of base bitumens, HMA0 and FWMA0 extracted bitumens. 

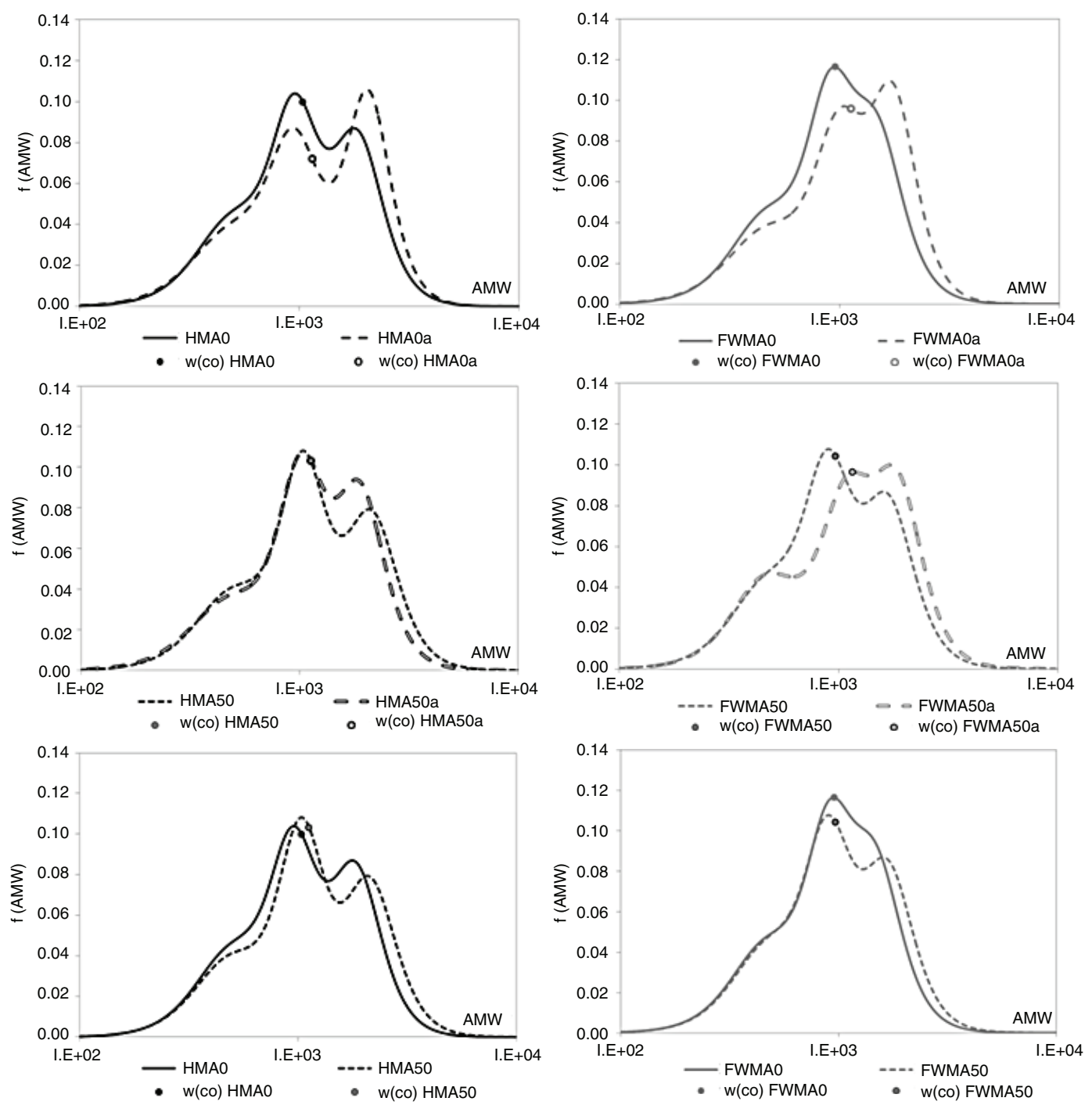

FIGURE 13. AMWD of the extracted bitumens by RAP and ageing state.
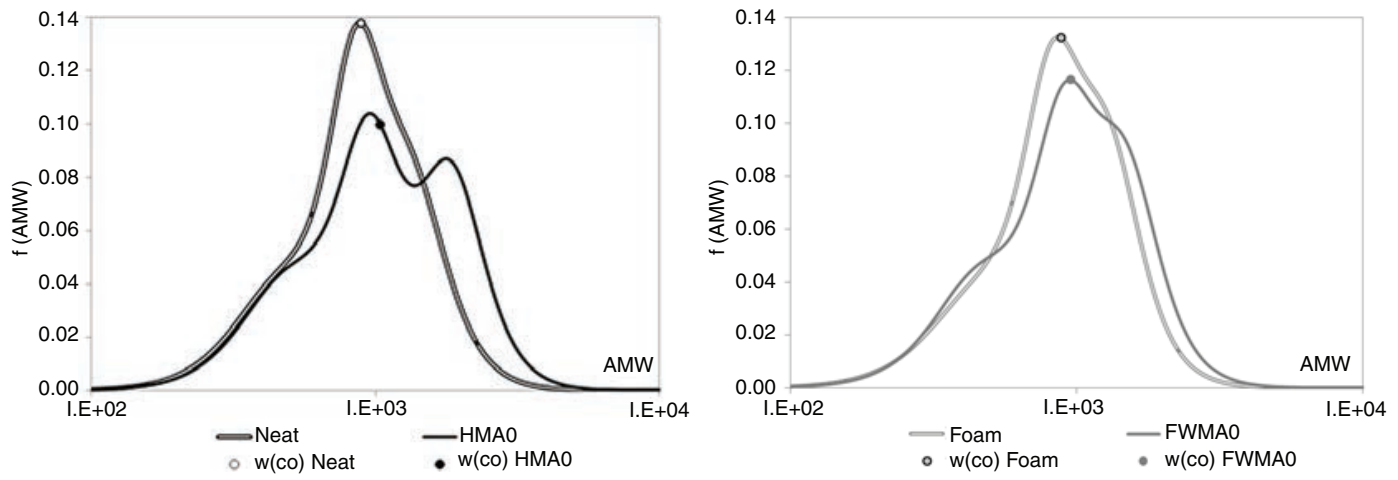

FIGURE 14. AMWD of the base bitumen and the extracted binder from the mixture. 
and resins) (34) that may be evolving, but also the appearance of the second peak as part of the absorption of resins by the asphaltenes fraction and the possible clustering that is induced. On the other hand, the difference on manufacturing temperatures shows a lighter evolution of the AMWD in the case of the FWMA bitumens.

\section{CONCLUSIONS}

In this paper, a comparison between the foaming technique for WMA production and a conventional HMA is carried out. Both mixes include the addition of 50\% RAP. Ageing of the asphalt is simulated using a laboratory adapted ageing protocol. This work is focused on the comparison of the mechanical performance of the mixtures and their bitumens, evaluated through the impact on the AMWD of the bitumens, calculated from rheological measurements through the $\delta$-method. The results obtained during the investigation led to the following conclusions:

i. Regarding bitumen performance, the foaming process ages the bitumen to a lower degree during manufacture compare to the conventional procedure. When long term ageing is applied, the levels become comparable in both cases. Similarly, the hardening experienced when RAP is added is less pronounced due to the already aged bitumen present in the RAP.

ii. Concerning the fatigue related performance, the addition of RAP increases in general the performance of the mixture, both for conventional and foamed warm mixtures. However, when RAP is added or ageing takes place, the fatigue slope increases and consequently, the fatigue resistance of the material tends to be more sensitive to the strain level.

iii. The lack of stiffness found for the FWMA process may be related to the reduced ageing of bitumen during the manufacturing process. In this case, more research is required to clarify these tendencies, and different amounts of RAP should be considered.

iv. The application of the $\delta$-method reveals contrasting ageing effects on the AMWD for the different processes, as well as the influence of RAP addition. The general pattern observed on the AMWDs is a decrease of the lower molecular weight fractions and an increase of the high molecular weight fractions due to ageing for the samples with or without RAP. Compared to the FWMA technique, the HMA production process induces a significant displacement of the distribution towards higher AMW. After ageing or RAP addition the distributions tend to be similarly shifted for the two processes.

v. Combined with standard bitumen testing, the $\delta$-method appears to be a powerful tool for the quantification of structural evolutions of bitumens, providing a clear visualization of the structural modifications induced. These results are likely to confirm that a structural interpretation of RAP addition and ageing evolution is possible with the $\delta$-method.

\section{ACKNOWLEDGEMENTS}

The research presented in this paper was carried out as part of the Marie Curie Initial Training Network (ITN) action, FP7-PEOPLE-2013-ITN. This project has received funding from the European Union's Seventh Framework Programme for research, technological development and demonstration under grant agreement number 607524.

\section{REFERENCES}

1. Zaumanis, M. (2010) Warm Mix Asphalt Investigation. Master Thesis, Riga Technical University.

2. Hill, B. (2011) Performance evaluation of warm mix asphalt mixtures incorporating reclaimed asphalt pavement. Thesis. University of Illinois at Urbana-Champaign.

3. Hamzah, M.O.; Jamshidi, A.; Shahadan, Z. (2010) Evaluation of the potential of Sasobit to reduce required heat energy and $\mathrm{CO}_{2}$ emission in the asphalt industry. J Clean Prod. 18[18], 1859-65. https://doi.org/10.1016/j. jclepro.2010.08.002.

4. Rubio, M.C.; Moreno, F.; Martínez-Echevarría, M.J.; Martínez, G.; Vázquez, J.M. (2013) Comparative analysis of emissions from the manufacture and use of hot and half-warm mix asphalt. J Clean Prod. 41, 1-6. http://dx.doi. org/10.1016/j.jclepro.2012.09.036.

5. Rubio-Gámez, M.C.; Menedez, A.; Moreno-Navarro, F.; Belmonte, A.; Ramirez, A. (2011) Mechanical properties of hot bituminous mixes manufactured with recycled aggregate of Silestone ${ }^{\circledR}$ waste. Mater Constr. 61[301], 49-60. http:// dx.doi.org/10.3989/mc.2011.52709.

6. Kristjansdottir, O. (2006) Warm Mix Asphalt for Cold Weather Paving. University of Washington.

7. D'Angelo, J.; Harm, E.; Bartoszek, J.; Baumgardner, G.; Corrigan, M.; Cowsert, J. et al. (2008) Warm-Mix asphalt : European Practice. FHWA-P1-08-007. Alexandria, Virginia.

8. Vaitkus, A.; Čygas, D.; Laurinavičius, A.; Perveneckas, Z. (2009) Analysis and evaluation of possibilities for the use of warm mix asphalt in Lithuania. Balt J Road Bridg Eng. 4[2], 80-6. http://dx.doi.org/10.3846/1822-427X.2009.4.80-86.

9. EAPA. (2014) The use of warm mix asphalt. European Asphalt Paving Association. www.eapa.org.

10. Mansfeld, R.; Barth, R.; Beer, F.; Breitbach, P.; Gogolin, D.; Pass, F. et al. (2009) Temperaturßabgesenkte Asphalte. Ratschläge aus der Praxis für die Praxis. Bonn, Germany.

11. Chiu, C.T.; Hsu, T.H.; Yang, W.F. (2008) Life cycle assessment on using recycled materials for rehabilitating asphalt pavements. Resour Conserv Recycl. 52, 545-56. http:// dx.doi.org/10.1016/j.resconrec.2007.07.001.

12. Xiao, F.; Amirkhanian, S.N.; Juang, C.H. (2007) Rutting Resistance of Rubberized Asphalt Concrete Pavements Containing Reclaimed Asphalt Pavement Mixtures. J Mater Civ Eng. 19[June], 475-83. http://dx.doi.org/10.1061/ (ASCE)0899-1561(2007)19:6(475).

13. Coppola, L.; Kara P.; Lorenzi, S. (2016) Concrete manufactured with crushed asphalt as partial replacement of natural aggregates. Mater Constr. 66[324]. http://dx.doi. $\mathrm{org} / 10.3989 / \mathrm{mc} .2016 .06515$.

14. Karlsson, R.; Isacsson, U. (2006) Material-Related Aspects of Asphalt Recycling - State-of-the-Art. J Mater Civ Eng. 18[February], 81-92. http://dx.doi.org/10.1061/ (ASCE)0899-1561(2006)18:1(81). 
15. Al-Qadi, I.L.; Elseifi, M.A.; Carpenter, S.H. (1998) Reclaimed Asphalt Pavement - A Literature Review. Research Report FHWA-ICT-07-001. Illinois Center for Transportation. Urbana, Illinois.

16. Roberts, F.L.; Kandhal, P.S.; Brown, E.R.; Lee, D.; Kennedy, T.W. (1996) Hot Mix Asphalt Materials, Mixture Design and Construction. 2nd Ed. Lanham, MD. NAPA Education Foundation.

17. Thyrion, F.C. (2000) Asphalt Oxidation, Asphaltenes and Asphalts. Developments in Petroleum Science, 40[B]. Elsevier, New York, USA. http://dx.doi.org/10.1016/ S0376-7361(09)70287-0.

18. Themeli, A.; Chailleux, E.; Farcas, F.; Chazallon, C.; Migault, B. (2015) Molecular weight distribution of asphaltic paving binders from phase-angle measurements. Road Mater Pavement Des. 16[S1], 228-44. http://dx.doi. org/10.1080/14680629.2015.1029667.

19. AFNOR. (2007) FR-EN 1426. Bitumen and bituminous binders. Determination of needle penetration, Association Française de Normalisation, (in French), On line at: https://www.boutique.afnor.org/norme/nf-en1426/bitumes-et-liants-bitumineux-determination-de-lapenetrabilite-a-1-aiguille/article/654516/fa140508. (2007).

20. AFNOR. (2007) FR-EN 1427. Bitumen and bituminous binders. Determination of softening point, Association Française de Normalisation, (in French), On line at: https://www.boutique.afnor.org/norme/nf-en-1427/ bitumes-et-liants-bitumineux-determination-du-point-deramollissement-methode-bille-et-anneau/article/767864/ fa140509 (2007)

21. LCPC. (2007) Fatigue carousel at IFSTTAR, Nantes [French]. Nantes, France.

22. Lopes, M.; Gabet, T.; Bernucci, L.; Mouillet, V. (2015) Durability of hot and warm asphalt mixtures containing high rates of reclaimed asphalt at laboratory scale. Mater Struct. 48, 3937 http://dx.doi.org/10.1617/s11527-014-0454-9.

23. De la Roche, C.; Van de Ven, M.F.C.; Planche, J.P. et al. (2013) Hot Recycling of Bituminous Mixtures. Advances in Interlaboratory Testing and Evaluation of Bituminous Materials - RILEM State-of-the-Art Reports. Springer Netherlands.http://dx.doi.org/10.1007/978-94-007-5104-0_7.

24. AFNOR. (2012) FR-EN 12697-26. Bituminous mixturesTest methods for hot mix asphalt - Stiffness, Association Française de Normalisation, (in French), Online at: https:// www.boutique.afnor.org/norme/nf-en-12697-26/melangesbitumineux-methodes-d-essai-pour-melange-hydrocarbonea-chaud-partie-26-module-de-rigidite/article/625941/ fa167950. (2012).

25. AFNOR. (2013) FR-EN 12697-24. Bituminous mixtures Test methods for hot mix asphalt - Resistance to fatigue, Association Française de Normalisation, (in French), On line at: https://www.boutique.afnor.org/norme/nf-en-1269724/melanges-bitumineux-methodes-d-essai-pour-melangehydrocarbone-a-chaud-partie-24-resistance-a-la-fatigue/ article/801894/fa174514. (2013).

26. Moutier, F. (1991) Etude statistique de l'effet de la composition des enrobés bitumineux sur leur comportement en fatigue et leur module complexe. Bull Liaison du Lab des Ponts Chaussées, 172, 71-9.

27. AFNOR. (2013) FR-EN 12697-3. Bituminous mixtures Test methods for hot mix asphalt - Bitumen recovery: Rotary evaporator, Association Française de Normalisation, (in French), On line at: https://www.boutique.afnor.org/ norme/nf-en-12697-3/melanges-bitumineux-methodesd-essai-pour-melange-hydrocarbone-a-chaud-partie-3extraction-des-bitumes-a-l-evaporateur-rot/article/805128/ fa179767. (2013).

28. Petersen, J.C. (2009) A Review of the Fundamentals of Asphalt Oxidation: Chemical, Physicochemical, Physical Property, and Durability Relationships. Transportation Research Board. Washington.

29. Liu, M.; Lunsford, K.M.; Davison, R.R.; Glover, C.J.; Bullin, J.A. (1996) The kinetics of carbonyl formation in asphalt. AIChE J. 42[4], 1069-76. http://doi.wiley. com/10.1002/aic.690420417.

30. Marsac, P.; Piérard, N.; Porot, L.; Van den bergh, W. Grenfell, J; Mouillet, V. et al. (2014) Potential and limits of FTIR methods for reclaimed asphalt characterisation. Mater Struct. Springer, 47[8], 1273-1286. http://dx.doi. org/10.1617/s11527-014-0248-0.

31. Read, J.; Whiteoak, D. (2003) The Shell Bitumen Industrial Handbook. 5th ed. Thomas Telford Publishing (2003).

32. Tuminello, W.H.; Cudré-Mauroux, N. (1991) Determining molecular weight distributions from viscosity versus shear rate flow curves. Polym Eng Sci. 31[20], 1496-507. http:// doi.wiley.com/10.1002/pen.760312009.

33. Wu, S. (1988) Characterization of Polymer Molecular Weight Distribution by Transient Viscoelasticity: Polytetrafluoroethylenes. Polym Eng Sci. 28[8], 538-543. http://doi.wiley.com/10.1002/pen.760280809.

34. Lesueur, D. (2009) The colloidal structure of bitumen: consequences on the rheology and on the mechanisms of bitumen modification. Adv Colloid Interface Sci. 145[1-2], 42-82. http://dx.doi.org/10.1016/j.cis.2008.08.011.

35. Tuminello, W.H. (1986) Molecular weight and molecular weight distribution from dynamic measurements of polymer melts. Polym Eng Sci. 26[19], 1339-47. http://doi.wiley. com/10.1002/pen.760261909.

36. Zanzotto, L.; Stastna, J.; Ho, S. (1999) Molecular weight distribution of regular asphalts from dynamic material functions. Mater Struct. 32[April], 224-9. http://dx.doi. org/10.1007/BF02481519.

37. Kodippily, S.; Holleran, G.; Holleran, I.; Henning, T.; Wilson, D. (2014) Performance of Recycled Asphalt Pavement Mixes - Comparing New Zealand Experience to American Experience. TRB 93rd Annual Meeting.

38. AFNOR. (2008) FR-EN 13108-1. Bituminous mixtures Material specifications - Asphalt Concrete, Association Française de Normalisation, (in French), On line at: https:// www.boutique.afnor.org/norme/nf-en-13108-1/melangesbitumineux-specifications-des-materiaux-partie-1-enrobesbitumineux/article/674259/fa101257. (2008).

39. Chailleux, E.; Ramond, G.; Such, C.; de La Roche, C. (2006) A mathematical-based master-curve construction method applied to complex modulus of bituminous materials. Road Mater Pavement Des. 7[sup1], 75-92. http://dx.doi.org/10.1 080/14680629.2006.9690059.

40. Le Guern, M.; Chailleux, E.; Farcas, F.; Dreessen, S. Mabille, I. (2010) Physico-chemical analysis of five hard bitumens: Identification of chemical species and molecular organization before and after artificial aging. Fuel. 89[11], 3330-9. https://doi.org/10.1016/j.fuel.2010.04.035. 